\title{
XIX a. LIETUVOS DVARŲ VALDŲ PLANŲ YPATUMAI
}

\author{
Romualdas Girkus ${ }^{1}$, Viktoras Lukoševičius ${ }^{2}$ \\ ${ }^{1}$ Aerogeodezijos institutas, Pramonès pr. 13, LT-51327 Kaunas, Lietuva, el.paštas: info@agi.lt \\ ${ }^{2}$ Kauno technologijos universitetas, Panevėžio institutas, Klaipédos g. 1, LT-37348 Panevėžys, Lietuva, \\ el.paštas: vikluk@midi.ppf.ktu.lt
}

\author{
Iteikta 20051105 , priimta 20060317
}

\begin{abstract}
Santrauka. Straipsnyje aptariami XIX a. pirmos pusès Lietuvos Vilkmergès pavieto dvarų valdų grafiniai dokumentai: Upytès pavieto Pakruojo ir Šeduvos dvarų valdų ir Rokiškio grafystės žemès valdų planai. Nagrinėjami planų sudarymo principai, aptariama autoryste, jų kryptingumas, masteliai, sutartiniai ženklai, apimamos teritorijos, gamybos technika, puošybos elementai. Analizuojami planuose pateiktų gyvenviečių, upių, ežeru, mišku, pelkių ir durpynų pavadinimai ir lyginami su nūdienos sunormintais jų pavadinimais. Konstatuojama, kad vietovardžiai ir vandenvardžiai iš esmès išlikę tapatūs. Labiau pakitę kai kurių ežerų vardai.
\end{abstract}

Prasminiai žodžiai: žemès valdos, dvarai, planų sudarymo principai, vietovardžiai, Pakruojis, Šeduva, Rokiškis, Litviniškès.

\section{Upytės pavieto Pakruojo ir Šeduvos dvarų valdų planai}

Planai sudaryti $1820 \mathrm{~m}$. Upytès matininko Jan Želigowski $65 \mathrm{~cm}$ pločio vatmano lapuose. Pakruojo plano lapo ilgis $-100 \mathrm{~cm}$, o Šeduvos $-113 \mathrm{~cm}$. Dvaru valdos išdèstytos planuose, jų plačioji dalis tęsiasi gulstinès plano kraštinès kryptimi. Pakruojo plane pažymètoji šiaurè nukreipta i kairę vertikaliają plano kraštinę $\approx 45^{\circ}$ azimutu, o Šeduvos plane $-\mathfrak{i}$ dešinę vertikaliają plano kraštinę $\approx 120^{\circ}$ azimutu. Tai byloja apie laisvai pasirinktą planų orientavimą.

Aplinkinè dvaro valdų siena planuose pažymèta riboženkliais, atraminius riboženklius ženklinant skaitmenimis. Su upėmis sutampančios ribos kartografuotos minint upių pavadinimus, pažymètos ribu kertamos upių atkarpos ir tụ upių vardai. Planai piešti, gan saviti. Plano viduje išdestyti gyvenviečiu perspektyviniai spalviniai piešiniai. Žymimos gyvenviečiu kategorijos (kaimas, palivarkas, eiguva) ir pavadinimai. Žymejimas primena XVI-XVII a. senuosiuose žemèlapiuose miestams vaizduoti naudotus profilinius sutartinius ženklus (S. Miunsteris, O. Magnusas, V. Grodeckis ir kt.). Gyvenvietės pieštos miniatiūru piešimo technika, išskiriant bažnyčias, dominuojančius pastatus ir medžius. Gyvenviečiu pavadinimai irašyti ¿mantriu šriftu lenkų kalba.

Skersiniai masteliai nubraižyti planu apačioje - su prierašu lenkiškai apie masteli - 100 lietuviškų šniūrų. Iš prierašo akivaizdu, kad tiesinio mastelio atitikmuo - 100 lietuvišku šniūrų. Vilniaus universiteto Geodezijos katedros vedèjo Antano Šakinio (1790-1842) 1829 m. išleistoje knygoje „Miernictwo i rownowaženie“ nurodoma, kad Lietuvoje taikomas matas šniūras metrineje sistemoje prilyginamas 48,72591 metro [1]. Planų masteliams nustatyti išmatuotą plane skersinio mastelio pagrindo liniją $(16,0 \mathrm{~cm})$ palyginame su $100 \times 48,726 \mathrm{~m}$ ir šiuo santykiu gauname skaitmenini planų mastelį $\sim$ : 30000 . Ši planų skaitmenini mastelį anksčiau apskaičiavo Lietuvos kartografijos žinovas J. Deksnys (1904-1989), 100 lietuvišku šniūru atitikmeniu plane laikydamas 1/4 alkūnès. Kadangi pagal A. Šakini šniūre telpa 75 alkūnès, tai $1 / 4$ alkūnès santykis su 100×75 atitinka skaitmenini masteli 1:30 000 .

Planuose su meniškais atributais ibrèžtos orientavimo kryptys. Pakruojo plane - su rozete, o Šeduvos plane - piešiniu plunksna. Planų apatiniuose kampuose irašai lenkų kalba apie planų sudarymą. Geometras Jan Želigowski teigia, kad „Sienu aukščiausios instancijos pavedimu, dvaro žemių bendrai ribai nustatyti Upytès paviete atliktas kapčių supylimas ir ju geometrinis pažymèjimas plane, nurodant užribio valdas“. Planų apačioje ranka rašyti sienų arbitrų irašai, tvirtinantys geometro J. Želigowski sudaryto plano tikroviškumą. Čia planų panašumas baigiasi, nes užribio informacija pateikta skirtingai.

Pakruojo plane užribio gyvenvietès pažymètos tik pavadinimais jų vietose plane, bet dukart didesniu šriftu, palyginti su dvaro valdu gyvenvietemis. Šeduvos planuose su meniškais atributais ibrèžtos užribio gyvenvietės, šalia pažymètos išorinès aplinkinès dvaro valdų ribos ,nuo... iki...“, todèl pagal reikalaujamą linksni kilmininku. Pavieniais atvejais vietoj gyvenviečiu pažymètos užribio valdų savininkų pavardès (Jasienskiego, Ganekoffa, Miksewica ir pan.). Gyvenvietès, kurios ribojasi su Šiauliu pavietu, nekonkretizuotos, o irašyta „Šiaulių priklausomybės 
kaimai“. Šeduvos plane eiguvos neitvardytos konkrečiais vardais, o tik gyvenviečiu pavadinimams analogišku šriftu pažymètos bendriniu užrašu ,lesnik“.

Pakruojis, nors plane ivvardytas miestu, iš dvaro valdų neišskirtas, todèl teigtina, kad tuo laikmečiu miestas neturejo savivaldos ir priklausė dvaro savininkui grafui Ropui. Gi Šeduvos valdų plane Šeduva kaip miestas ribomis išskirtas iš bendrų dvaro valdų. Šeduvą su apylinkėmis $1798 \mathrm{~m}$. kunigaikštis S. Poniatovskis pardavè T. Ropui, kuris netrukus dvaro centrą perkèle i Raudondvario gyvenviete.

Šeduvos dvaro valdų plane atskirai irašas apie plano žemių sumažinimą keturiose plano vietose, nurodyti gretimi riboženklių numeriai ar žemių valdų savininko pavardè. Plotai nurodyti margais ir kvadratiniais prentais. Pagal minètuosius A. Šakinio matų atitikmenis metrinèje sistemoje margas prilygintas 0,7122645 hektaro. Marga sudare $300 \mathrm{kv}$. prentuc, tad kvadratinis prentas metrineje sistemoje lygus 0,2374215 aro. Perskaičiuodami ketvirtosios plano žemių sumažinimo vietos sienos kertamos kartografuoto, bet neįvardyto Paežerių ežero dalies 15 margų ir $282 \mathrm{kv}$. prentų plotą i metrinę sistemą, gauname 15,94 margo $\times 0,71226=11,33$ ha. Ežeras nepriklausè dvaro valdoms, todèl šiuo plotu sumažintos valdos. Šiandien Paežerių ežero nebèra, jis sunyko patvanka sujungus su Arimaičių ežeru.

Teigtina, kad planuose pažymètos gyvenvietès ir upès bei jų pavadinimai daugiausia yra išlikę. Dèl melioracijos darbų sovietmečiu išnyko Pakruojo plane prie Mūšos upès buvę kaimai Sidaugai (Sydowgie) dešiniajame krante, Puknioniai (Pukniany) ir Bagdoniškiai (Bogdanele) - kairiajame krante [2]. 1976 m. gyvenviečių sąrašuose šie kaimai dar įvardyti [3], o 1987 m. topografiniame M 1: 50000 žemėlapyje jų jau nebėra. Šeduvos plane Rimaičiu (Rymayc) gyvenvietė šiandien vadinama Arimaičiais. Matyt, taip atsitiko Arimaičio ežerą Rusijos topografiniuose žemèlapiuose ivvardijus Rimaičiu. Vèliau šis ežero vardas buvo žymimas kaip antrinis [4, 5].

Planuose minimi gyvenviečiu ir upių pavadinimai bei nūdienos šių vietovardžių atitikmenys pateikti 1,2 lentelèse, skiriant juos i dvi kategorijas - planų valdose ir užribyje.

\section{Rokiškio grafystès žemès valdụ planai}

Grafo Ignaco Tyzenhauzo valdas žymi trys Rokiškio grafystei priklausę žemès valdų grafiniai dokumentai,

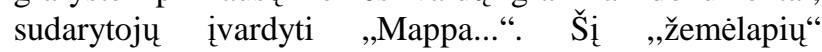
pavadinimo pirmaji žodi vartosime aptardami žemių valdu planus.

Žemès valdu planu paskirtis ir tarpusavio sasaja. Du 1810 m. Žemėlapiai skirti LITVINIŠKĖS (Litwiniszki) ir SKREBIŠKĖS (Skrobiszki) palivarku valdoms. Šie Žemėlapiai tarpusavyje ribojasi, o trečiasis - $1848 \mathrm{~m}$. ROKIŠKIO (Rakiskiego) grafystès valdų žemèlapis apima ir šių dviejų palivarkų valdas (jos sudaro tik apie dešimtadali grafystès valdų teritorijos).

Originalumas. Pirmieji du žemèlapiai - spalvoti autoriniai originalai su piešiniais, puošybos elementais ir ¿mantriu šriftu rašytais titulais, o trečiasis - gautas spaudos būdu, tad yra be piešinių ir puošybos, tačiau titulo šriftas stambus ir užima nemažą lapo plotą. Dèl žemėlapių amžiaus ir šrifto imantrumo nèra paprasta teisingai perskaityti titulus, tad pateikiame laisvus vertimus. Litviniškių valdų žemėlapio (1 pav.) titule įrašyta: žemėlapis „LITVINIŠKIU palivarko, įeinančio i ROKIŠKIO pagrindines valdas, išsidèsčiusias VILKMERGĖS paviete, esančias Jo Didenybès grafo IGNACO TYZENHAUZO, Lietuvos pėstininku armijos gvardijos šefo ir aukštų ordinų kavalieriaus, nuosavybeje, geometriškai išmatuoto 1810 metais“.

Skrebiškiu valdǔ žemèlapyje atitinkamai irašyta: žemėlapis ,SKREBIŠKIŲ palivarko, įeinančio į Rokiškio pagrindines valdas, išsidèsčiusias VILMERGËS paviete, esančias Jo Didenybès grafo IGNACO TYZENHAUZO, Lenkijos pèstininku armijos gvardijos šefo ir aukštu ordinų kavalieriaus, nuosavybeje, geometriškai išmatuoto 1810 metais “.

Lapu matmenys ir ju orientavimas. Litviniškių valdos braižytos $60 \times 50 \mathrm{~cm}$, o Skrebiškių valdos $88 \times 68 \mathrm{~cm}$ lapuose, orientuojant lape pagal ilgają lapo kraštinę. Pasaulio krypčių atžvilgiu šie du žemèlapiai orientuoti vienodai - i vakarus. Rokiškio grafystès žemèlapis didelių matmenų $(125 \times 240 \mathrm{~cm})$, suklijuotas iš aštuonių spaudos lapų. Grafystès teritorija orientuota pagal trumpają suklijuoto žemėlapio kraštinę. Kadangi grafystès valdos išsitęsusios šiaurès-pietų kryptimi, tad žemèlapio lapas pasaulio krypčiu atžvilgiu orientuotas i rytus. Sutapdinant žemėlapių tą pačią teritoriją, tampa akivaizdu, kad pirmieji du žemèlapiai, palyginti su Rokiškio grafystès žemėlapiu, skiriasi išsidėstymu $180^{\circ}$ pagal jo orientavimą.

Masteliai. Litviniškių ir Skrebiškių valdų žemėlapiai to paties mastelio. Jis nustatomas iš nubraižytų tapačių skersinių mastelių. Litviniškių lape virš mastelio brěžinio papildomas irašas „Skala zawiera sznurow 30“. Žinant, kad lietuviškas šniūras lygus 48,73 metro [1] ir išmatavus skersinio mastelio ilgi $(11,6 \mathrm{~cm})$, galima rasti žemèlapio skaitmenini masteli [11,6 cm: $(48,73 \times 30) \mathrm{m}]=1: 12600$. Rokiškio grafystès žemèlapio skersinio mastelio ilgis $18 \mathrm{~cm}$ ir užrašas prie mastelio „Podzialka miary Litewskiej od sznurow 100“ leidžia analogiškai atlikti skaičiavimus ir gauti skaitmenini masteli - 1:27 000 .

Apimamos teritorijos. Litviniškių valdos apima šias žemėlapyje pažymètas gyvenvietes: Pužanice (Pužionys), Ropiszki (Ruopiškis), Dyliszki (Diliškiai), Natkuszki (Natkuškiai), Zarzecze (Paupè), Nowa (Ulytèlè), Litwiniszki (Sèlynè). Pažymèti kaimai, su kuriais ribojasi valdų teritorija: Sedzian (Sèdžiūnais), Sapeciun (Spiečiūnais), Pirogiszkami (Pyragiškiais), Dydejo (Dideja), Kawelami (Koveliais), Audras (Audra), Skrobiszkiemi (Skrebiškemis) [2, 3]. 
1 lentelè. Šeduvos dvaro valdų plano vietovardžiai ir vandenvardžiai

Table 1. Names of the toponyms and hydronims in the plan of land estates of Šeduva

\begin{tabular}{|c|c|c|c|c|}
\hline \multirow{2}{*}{$\mathrm{Nr}$. } & \multicolumn{2}{|c|}{ Dvaro valdose } & \multicolumn{2}{|c|}{ Dvaro užribyje } \\
\hline & $1820 \mathrm{~m}$. & Nūdienos [6] & $1820 \mathrm{~m}$. & Nūdienos [6] \\
\hline 1 & wies Bobruie & Bebrujai & Auksztolok & Aukštelkių \\
\hline 2 & wies Bowkie & Baukiai & Buczun & Bačiūnų \\
\hline 3 & wiesDrowmiany & Draumėnai & Butan & Butėnu \\
\hline 4 & wies Dervele & Derveliai & Burbiszek & Burbiškio \\
\hline 5 & Czerwony Dwor & Raudondvaris & Czelk & Čelkiu \\
\hline 6 & foliwark Emalija & Amalija & Dulkiszek & Dulkiškių \\
\hline 7 & wies Gimbogala & Gimbogala & Dewoniszek & Dovainiškio \\
\hline 8 & wies Jasiulaycie & Jasvilaičiai & Darguž & Dargužių \\
\hline 9 & wies Kauksnuje & Kauksnujai & Jasauc & Jasaičių \\
\hline 10 & foliwark Kreiwokiszki & Kreivokiškis & Januszkan & Januškonių \\
\hline 11 & foliwark i wies Laudyszki & Liaudiškiai & Kurkli & Kurklių \\
\hline 12 & wies Medykany & Medikoniai & Kaulaliszek & Kaulališkių \\
\hline 13 & foliwark Mažaycie & Mažaičiai & Karklaic & Karklaičių \\
\hline 14 & wies Olksnupie & Alksnupiai & Maldziun & Maldžiūnų \\
\hline 15 & foliwark $i$ wies Puipy & Puipiai & Nemaniun & (Nemaniūnų mšk.) \\
\hline 16 & wies Poieziory & Paežeriai & Plebanii Szadowskiey & Kleboniškių \\
\hline 17 & wies Powartycze & Pavartyčiai & Poabel & Paobeliu \\
\hline 18 & wies Pakalniszki & Pakalniškiai & Przestowian & Prastavoniu \\
\hline 19 & foliwark Radwilany & Radviloniai & Rymayc & Arimaičių \\
\hline 20 & wies Roginiany & Raginènai & Sturyszek & Stūriškių \\
\hline 21 & miasto Szadow & Šeduva & Slek & Sliekių \\
\hline 22 & wies Sznukany & Šniukoniai & Worduksan & Vardukšnių \\
\hline 23 & wies Saukiany & Šaukoniai & rzeka Berža & upè Beržè \\
\hline 24 & wies Syleykany & Šileikoniai & rzeka Dowgiwena & upė Daugyvenè \\
\hline 25 & wies Weryszki & Vèriškiai & rzeka Saaka & upé Šaka \\
\hline 26 & wies Woydziulany & Vaidulioniai & & \\
\hline 27 & wies Zylany & Žilioniai & rzeka Jeziorka & upė Ežerèlè \\
\hline 28 & wies Zyborty & Žybartai & rzeka Niawduva & upé Niauduva \\
\hline
\end{tabular}

2 lentelè. Pakruojo dvaro valdų plano vietovardžiai ir vandenvardžiai

Table 2. Names of the toponyms and hydronims plan of land estates of Pakruojis

\begin{tabular}{|c|c|c|c|c|}
\hline \multirow{2}{*}{ Nr. } & \multicolumn{2}{|c|}{ Dvaro valdose } & \multicolumn{2}{|c|}{ Dvaro užribyje } \\
\hline & $1820 \mathrm{~m}$. & Nūdienos [6] & $1820 \mathrm{~m}$. & Nūdienos [6] \\
\hline 1 & wies Akmenèle & Akmenèliai & Bolsie & Balsiai \\
\hline 2 & wies Beszany & Bešoniai & Bogdanele & Bagdoniškiai \\
\hline 3 & wies Cholewy & Kalevai & Dowoniszki & Dovainiškis \\
\hline 4 & wies Chwiedory & Kvedarai & Judiszky & Judiškiai \\
\hline 5 & wies Daukszygole & Daukšigaliai & Juszkany & Juškoniai \\
\hline 6 & wies Kolicze & Kolyčiai & Klawany & Klovainiai \\
\hline 7 & wies Karaszyle & Karašilis & Kapczuny & Kapčiūnai \\
\hline 8 & wies Kondracie & Kundročiai & Labory & Laborai \\
\hline 9 & wies Koreywiszki & Kareiviškiai & Leypuszky & Laipuškiai \\
\hline 10 & wies Možeykany & Mažeikoniai & Meyluny & Meilūnai \\
\hline 11 & wies Noreyikay & Noreikoniai & Pacuny & Pociūnai \\
\hline 12 & wies Osze & Uošas & Poieziory & Paežeriai \\
\hline 13 & wies Paszkany & Poškiečiai & Preyczuny & Preičiūnai \\
\hline 14 & dwor Pokroie & & Pukniany & Puknioniai \\
\hline 15 & miasto Pokroie & Pakruojis & Raczkaycie & Ročkaičiai \\
\hline 16 & foliwark nove Pokroie & Pakruojis & Siecie & Siečiai \\
\hline 17 & foliwark mate Pokroie & & Uzubale & Užubeliai \\
\hline 18 & wies Palecie & Paliečiai & Woronce & Voroniai \\
\hline 19 & wies Powerdunie & Paverdeniai & rzeka Musza & upė Mūša \\
\hline 20 & foliwark Polaszmen & Palašmenis & rzeka Kroia & upé Kruoja \\
\hline 21 & foliwark Podowgiwen & Padauguva & rzeka Dowgiwena & upé Daugyvenè \\
\hline 22 & wies Sygutany & Sigutėnai & rzeka Jeziorka & upé Ežerèlè \\
\hline 23 & wies Sydowgie & Sidaugai & buczay Lasznena & upè Lašmuo \\
\hline 24 & wies Toliszany & Telišoniai & buczay Obela & upė Obelè \\
\hline
\end{tabular}



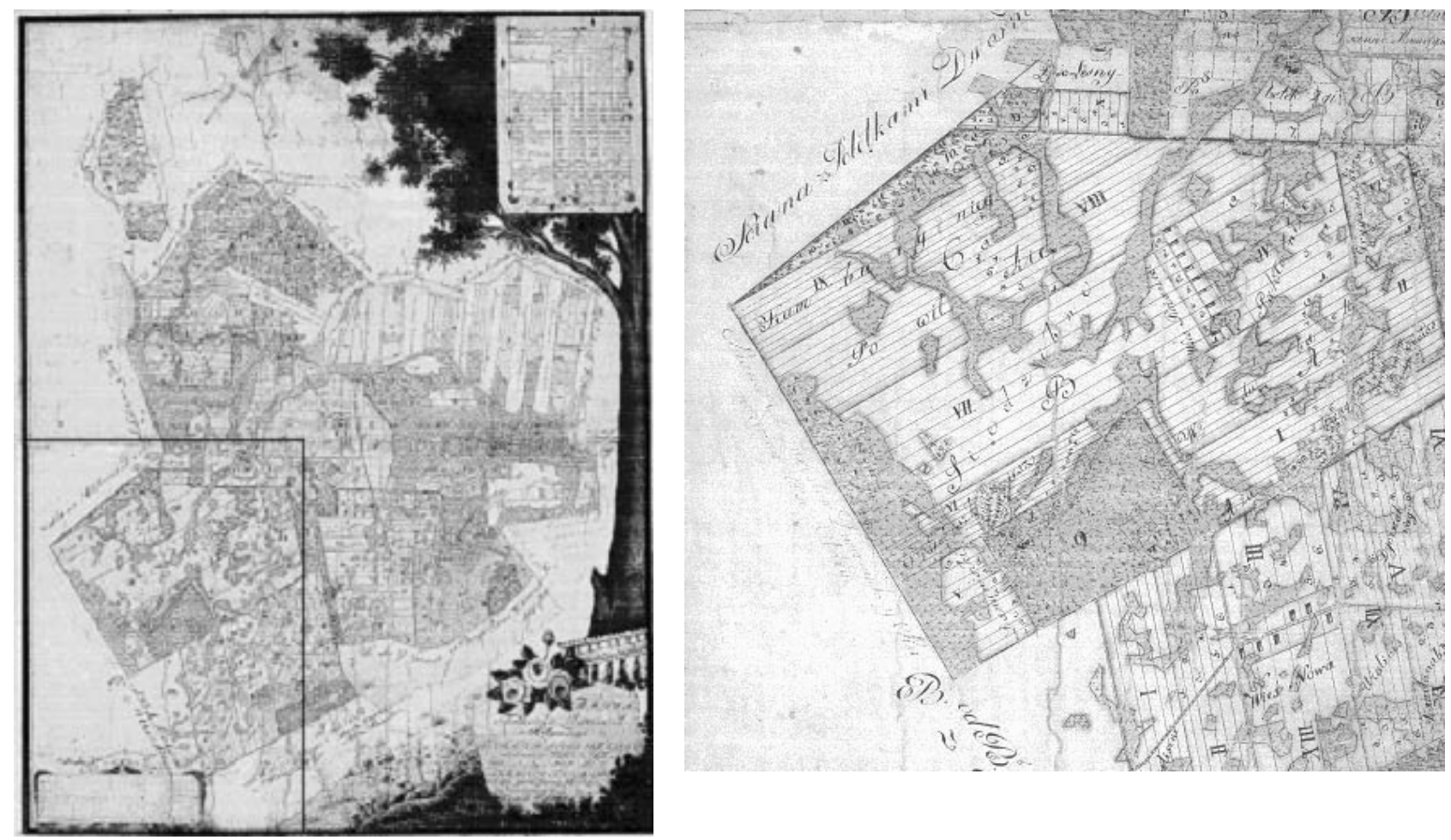

1 pav. Rokiškio grafystės Litviniškių žemės valdų M1:12 600 planas, sumažintas 6,4 karto, ir plano fragmentas, sumažintas 1,8 karto Fig 1. The plane of land estates of Litviniškès in Rokiškis county, scale 1:12 600 (decreased by 6,4 times) and a fragment of the plan (decreased by 1,8 times)

Skrebiškiu valdos apima šias žemèlapyje pažymètas gyvenvietes: Kosie (Kuosiai), Aukstokalnie (Aukštakalniai), Tataryszki (Totoriškiai), Giruny (Giriūnai), Romaneycie (Ramonaičiai), Bohuszyszki (Baušiškiai), Warle (Varliai). Pažymèti kaimai, su kuriais ribojasi valdų teritorija: Komajami (Kamajais), Olseta (Alseta), Kroupiami (Kraupiais), Pužanami (Pužioniais), Rogielami (Rageliais) [2, 3].

Rokiškio grafystès žemèlapis apima šiuos palivarkus ar dvarus su jų valdomis: Oknista (Aknysta), Wysoki dwor (Aukštadvaris), Wederuwszcyna (Veduviškis), Lukszty (Lukštai), Ignalin (Ignotiškis), Julianow (Uljanava), Rakiszki (Rokiškis), Skiemiany (Skiemai), Litwiniszki (Litviniškès), Rakiszeczki (Rokiškèliai), Skrobiszki (Skrebiškès), Dogile (Dagiliai) ir Komaje (Kamajai).

Rokiškio žemèlapio apžvalga. Šiame žemėlapyje (2 pav.) pateikta legenda, kurios nėra palivarku žemėlapiuose. Penkiaspalvio žemėlapio legendoje 23 sutartiniai ženklai: išskirtos žemès naudmenos, mišku rūšys, skirstomos pelkès, hidrografija, keliai, aukštumos, ivvairiarūšès sienų ribos. Sienų riboms legendoje skirta daugiausiai sutartinių ženklų. Jomis ribojamos palivarku valstybinès, nuomojamos, nenaudojamos, bendro naudojimo, konfiskuotos žemès.

Žemèlapyje esanti Aknystos palivarko teritorija 1920 m. ièjo i Latvijai perduotas žemes mainais i Palangos pajūrí. Pasienyje su žemèlapio laikmečio Kurliandija latviški vietovardžiai: vietovė Lelas Puras, miškas Kunga, miškas Welna wecymu, vietovè Priede ir pan.
Žemèlapio kūrimo metu Karčemos buvo minètini objektai, todèl jos irašytos net žemèlapio titule. Žemèlapyje pažymètos ir ịvardytos prieš pavadinimą rašant ir bendrinius trumpinius „k.“”, „kar.,“ arba netrumpinant „karcma“, pagal karčemos kategoriją. Karčemos daugeliu atvejų ikurtos šalia gyvenviečių ir ivvardytos tų gyvenviečių pavadinimais: Wobole (Vaboliai), Pokape (Pakapè), Wizunka (Vyžuona), Tataryszki (Totoriškiai), Stefance (Steponiai), Wejdelance (Vaidlėnai) ir pan. Dalis karčemų ỉvardytos kitų vietovès objektu vardais: Rago Galwa (vietovè ties siena su Kurliandija), Skardubie (upe Skardupis), Winksznini (vietovè Vinkšnynè), Rudbalis (durpynas), Lukszta (upè Lukšta) [2, 3].

Pagal šiuolaikinius hidrografijos duomenis [7, 8], identifikuojama dauguma žemėlapio hidronimų. Tai Wižūna (Vyžuona), Wengierynka (Vingerinè), Milžupis (Milžupys), Prudupis (Prūdupys), Elksynta (Alsinta), Oknista (Aknysta), Jodupis (Juodupys), Lukszta (Lukšta), Szetekszna (Šetekšna), Leszkupis (Leškupys), Beržona (Beržiena), Kieulupis (Kiaulupis), Loukupis (Laukupys), Luszna (Lūšna). Dalies vandens tėkmiu vardų nerasime šiandienos oficialiuose hidronimu dokumentuose: Ragupis, Szakupis, Skirsa, Margupis, Oldra, Asitupis, Pokrewna.

Mažai ežeringoje Rokiškio grafystès teritorijoje kartografuoti ežerai daugiausia įvardyti. Tai Szaszkinis (Armoniu), Skiautaryszki (Ignotiškio), Wižunki (Vyžuona), Audra (Audrelis), Olseta (Alseta), Lolu (Luolys), Komais (Petrošiškio), Potrakis (Aukštakal- 
niu), Szeszkinis (Mitragalys), Busznis, kuris šiandien žemėlapiuose kartografuojamas be vardo [2, 8].

Dauguma mišku plotų žemèlapyje ivvardyti savaisiais vardais: Kiekutynas, Dyrzyszki, Warpines, Kazabalis, Medynes, Sala, Brastyne, Waisiszki, Plokas, Erolis, Szilas, Wersza wecymus ir pan. Kiti miškai turi vietovių vardus, prieš jų vardą žymimas bendrinis trumpinys URO (vietovè): URO Girel, URO Poluksnia, URO Szylei, URO Elksnes, URO Dagimas, URO Zylwities, URO Skamarokiszki ir pan.

Pelkès ir durpynai taip pat dažnai ivardyti analogiškai miškams: Raiste, Krakla, Wilka puras, Berža puras, URO Lapiena, URO Apideme, URO Skrytolowo ir pan.

Rokiškio grafystès žemèlapio titule ịrašyta:

„ROKIŠKIO grafystès žemių žemėlapis su palivarkais, miesteliais, visais užribiais ir karčemomis, ROKIŠKIO priklausomybès pagrindinèmis valdomis, išsidèsčiusiomis VILNIAUS gubernijoje VILKMERGĖS pavieto ROKIŠKIO, KAMAJŲ ir OBELIŲ parapijose, esančiomis Jo Didenybès grafo IGNACO TYZENHAUZO, Lietuvos pėstininkų armijos gvardijos šefo ir aukštų ordinų kavalieriaus, nuosavybèje, sudalintomis kvadratais ir pažymėtomis riboženkliais, išdèstytais nurodytoje žemèje su užribio nuorodomis ir geometriškai inventorizuotas pagal žemès istatymus diferencijuotomis ribomis, paženklintomis geometriškai 1848 metais liepos mėn. 1 dieną, sudarant žemėlapi geometro MICHAL SKINDER.“

\section{Išvados}

1. Žemių valdų planai su perspektyviniais gyvenviečiu piešiniais vietoj iprastos kartografuojamos valdų teritorijos - ganètinai saviti XIX a. pradžios kartografiniai dokumentai.

2. Litviniškių ir Skrebiškių žemėlapių sudarytojas juose savo pavardès neirašè. Kadangi šie žemèlapiai sudaryti tais pačiais metais, ir jų atlikimo stilius analogiškas puošyba, žemėlapio sudedamujų dalių išdèstymu ir net iš esmès tapačiais titulais, galima teigti ir apie tą patị autorių. Rokiškio grafystès žemèlapio sudarytojas savo vardą ir pavardę isirašè žemėlapio titule kaip ir Pakruojo bei Šeduvos dvarų žemių planų sudarytojas.

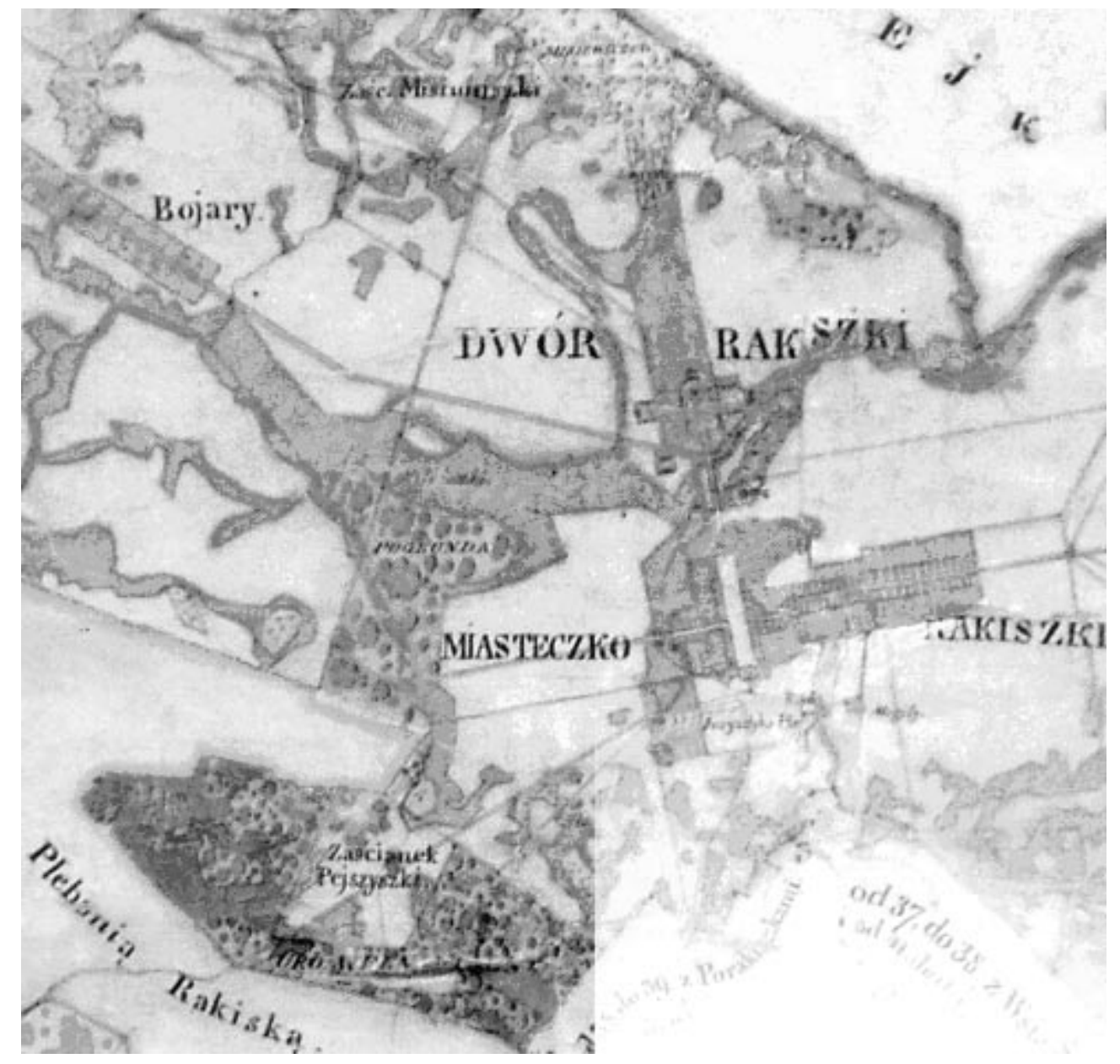

2 pav. Rokiškio grafystès žemėlapio dalis (M 1: 27000 sumažintas 10 kartu) ir žemėlapio centro fragmentas

Fig 2. Part of the map of Rokiškis county, scale 1:27,000 (decreased by 10 times) and a fragment of the map of the centre of Rokiškis 
3. Žemèlapių skaitmeniniai masteliai nustatyti pagal lietuviško šniūro ilgi, kuris skyrèsi nuo lenkiškojo. Šalia Rokiškio grafystès žemėlapio ir Pakruojo bei Šeduvos dvarų planų mastelio pažymėta, kad lietuviški šniūrai taikyti ir kitiems žemèlapiams, kuriuose šniūrų priklausomybè nenurodyta.

4. Vietovardžiai iš esmès yra išlaikę tapatumo elementus, ir šiandienos vietovardžių lietuviška interpretacija nekelia abejonių dèl jų lokalios tapatybès.

5. Rokiškio grafystès žemèlapiuose pasitaiko viena kita naujai pervardyta Litwiniszek (Sèlynè), Nowa (Ulytėlè) ar gyvenvieté, kurios pavadinimas - kalbinis vertinys Zarzecze (Paupè).

6. Rokiškio grafystès žemèlapyje daug vietovių pavadinimų rašyta lietuviškai ir net pagal teritorijos tarmę: pvz., Ažnugarei, Kieulupis, Amalu sala, Ežera bala, Medynas, Brastynès, Raistas, Girela, Pokalnia, Lunkielas ir pan.

7. Vandens tèkmių pavadinimai lengvai identifikuojami su šiandienos sunormintais jų vardais. Rokiškio grafystės žemėlapiuose pasitaiko ir prarastų hidronimų: pvz., Skirsa, Oldra, Asistupis, Pokrewna ir pan. Matomas didesnis ežerų vardų pokytis. Nemažai jų pervardyta: pvz., Skiautaryszki (Ignotiškio), Komais (Petrošiškio), Potrakis (Aukštakalniu), Szeszkinis (Mitragalys).

\section{Literatūra}

1. Szakin, Ant. Miernictwo i rownowaženie. Wilno, 1829, p. 153-155.

2. Topografiniai M 1:50 000 žemèlapiai PAKRUOJIS 5559/60-64, ŠEDUVA 55-59/55-59, BAISOGALA 5559/50-54, ŠIAULIAI 50-54/55-59, ROKIŠKIS 75-19/6064, OBELIAI 80-84/60-64, PANEMUNĖLIS 75-79/55-59, DUSETOS 80-84/55-59. Nacionalinė žemès tarnyba, 2002-2004.
3. Lietuvos TSR administracinio-teritorinio suskirstymo žinynas, II dalis. Vilnius: Mintis, 1976. 398 p.

4. Topografinis M 1:84 000 žemèlapis VIII-15. Generalinio štabo leidinys, 1897.

5. Topografinis M 1:100 000 žemèlapis N-34-12 (ШЕДУВА). Generalinio štabo leidinys, 1938.

6. Vietovardžiu žodynas. Vilnius: Mokslo ir enciklopediju leidybos institutas, 2002. 463. p.

7. Gailiušis, B. ir kt. Lietuvos upių hidrografija. Abècèlinè vietovardžiu rodyklè. Kaunas: Lietuvos energetikos institutas, 2001, p. 732-782.

8. Lietuvos Respublikos upių ir tvenkinių 2001-12-21; ežeru 2003-03-21 klasifikatoriai. Lietuvos aplinkos ministerija. Valstybès žinios, 2001-3888 ir 2003-1442.

Romualdas GIRKUS. Chief specialist for heritage. Institute of Aerogeodesy ( $\mathrm{Ph}+37037451$ 504).

A graduate of Kaunas Polytechnic Institute (now Kaunas University of Technology), geodetic engineer, 1962. Publications: over 20 scientific articles; participant of conferences in Latvia, Russia.

Research interests: history of geodesy and cartography.

Viktoras LUKOŠEVIČIUS. Doctor, Associate Professor. Dept of Civil Engineering Technique, Panevėžys Institute, Kaunas University of Technology ( $\mathrm{Ph}+37045435819$,

fax +37045516161 ).

A graduate of Kaunas Polytechnic Institute (now Kaunas University of Technology), geodetic engineer, 1962. Doctor's degree at Institute of Surveying, Aerial Photography and Cartography, Moscow, 1966. Publications: over 60 scientific articles; participant of conferences in USA, Brazil, Sweden, Norway, Russia. Fellowship Winner, NATO and Italy National Science Competition, 1996. Member of Association for the Advancement of Baltic Studies.

Research interests: history of geodesy and cartography. 